\title{
Appropriate use criteria for aortic stenosis: Guidelines or opinion?
}

\author{
Hersh S. Maniar, MD, and Marc R. Moon, MD
}

\author{
From the Division of Cardiothoracic Surgery, Washington University School of Medicine, St Louis, Mo. \\ Received for publication Feb 26, 2018; accepted for publication March 2, 2018; available ahead of print April 4 , \\ 2018. \\ Address for reprints: Marc R. Moon, MD, Division of Cardiothoracic Surgery, Washington University School of \\ Medicine, 3108 Queeny Tower, One Barnes Hospital Plaza, St Louis, MO 63110-1013 (E-mail: moonm@ \\ wustl.edu). \\ J Thorac Cardiovasc Surg 2018;156:119-21 \\ $0022-5223 / \$ 36.00$ \\ Copyright (C) 2018 by The American Association for Thoracic Surgery \\ https://doi.org/10.1016/j.jtcvs.2018.03.018
}

The 2017 appropriate use criteria (AUC) document for treatment of patients with severe aortic stenosis (AS) has been published simultaneously in the Journal of American College of Cardiology ${ }^{1}$ and the Journal of the American Society of Echocardiography ${ }^{2}$ and represents a combined work product of the American College of Cardiology, American Association for Thoracic Surgery, American Heart Association (AHA), American Society of Echocardiography, European Association for Cardio-Thoracic Surgery (EACTS), Heart Valve Society, Society of Cardiovascular Anesthesiologists, Society for Cardiovascular Angiography and Interventions, Society of Cardiovascular Computed Tomography, Society for Cardiovascular Magnetic Resonance, and Society of Thoracic Surgeons. The authors of the AUC document, Bonow and colleagues, 1,2 are to be congratulated for taking on the increasingly complex and rapidly changing world of AS and its therapies. The introduction of transcatheter aortic valve replacement (TAVR) and its subsequent approval by the US Food and Drug Administration changed the landscape of therapies available for patients with AS. TAVR has quite literally become the proverbial "game changer," allowing valve replacement in patients not previously considered candidates for aortic valve surgery and providing for other patients a truly less invasive option for valve replacement therapy. ${ }^{3-5}$

The recommendations in the AUC document are formatted with a similar organizational structure and illustrations as those of the well-established and recognized 2014 AHA $^{6}$ and 2017 European Society of Cardiology (ESC) and $\mathrm{EACTS}^{7}$ guidelines for valvular heart disease. Although the AUC document authored by Bonow and colleagues $^{1,2}$ does not specifically make class I, II, or II'" recommendations per se, it does use a rating system that categorizes interventions as appropriate, maybe appropriate, and rarely appropriate. The implication and language of the AUC designations track closely with class recommendations. For example, the "rarely appropriate" designation in the AUC document, ${ }^{1,2}$ defined as

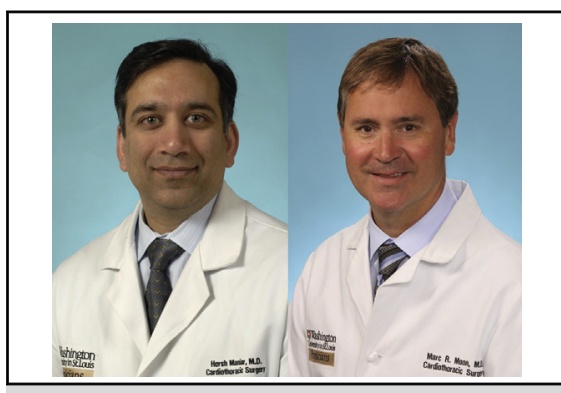

Hersh S. Maniar, MD (left), and Marc R. Moon, MD (right).

\section{Central Message}

Appropriate use criteria may help guide patient care, but the lack of a substantive foundation for some recommendations may lessen their value and handcuff the decision making of the heart team.

"treatment not generally acceptable and not a reasonable approach for the indication due to the lack of a clear benefit/risk advantage" is a near mimic of the class III recommendation from the $\mathrm{AHA}^{6}$ and ESC and EACTS guidelines, "Evidence or general agreement that the given treatment or procedure is not useful/effective, and in some cases may be harmful." A primary limitation inherent in the AUC document is that, in contrast to published valve guidelines, its recommendations are made without any reference to the level of evidence supporting a particular stance.

The AUC document, however, becomes particularly problematic when it designates a specific aortic valve replacement therapy as superior to another; with the most frequent example being an assertion that TAVR is superior to, or more appropriate in many circumstances than surgical aortic valve replacement (SAVR). This occurs with some frequency in Table 3 of the document when examining specific patient risks and comorbid conditions. There are several instances in which TAVR is considered "always appropriate," in contrast to SAVR, which is deemed "rarely appropriate" for the same scenario. This is an overreach by the AUC document given the current data, obtained from well-run, randomized trials, which have demonstrated noninferiority as the primary end point between TAVR and SAVR. This is also in contrast to the guidelines from the $\mathrm{AHA}^{6}$ and from the ESC and EACTS, ${ }^{7}$ which are consistent with one another and both refrain from such codified delineations. Current guidelines from the AHA and the European 
societies emphasize that when aortic valve replacement is indicated, both TAVR and SAVR therapies are equally recommended, in nearly all circumstances, empowering multidisciplinary heart teams with the freedom to choose the best therapy for a given patient. ${ }^{7,8}$

It is unlikely that the intent of this document was to undermine the multidisciplinary valve team, and Bonow and colleagues $^{1,2}$ clearly state that this document should not be used to "undermine clinical judgement" or influence payors with regards to reimbursement for procedures regardless of their appropriateness designation. Bonow and colleagues ${ }^{1,2}$ further emphasize that there must exist "flexibility within the guidelines." Bonow and colleagues ${ }^{1,2}$ cannot deny, however, that labeling potential therapies as "more appropriate" than another and in some cases designating an aortic valve replacement therapy as "rarely appropriate" are strong statements, with the potential to hamper clinicians as much as "guide" them. Equally likely is that clinicians will be caught in a "cross fire" when the AUC recommendations differ from those of established guidelines.

As an example, patients with a life expectancy of less than a year are not considered for valve replacement therapy by current guidelines and are to be considered for hospice or palliative balloon valvuloplasty. Although few, if any clinicians, would consider SAVR in this setting, it is surprising to see TAVR deemed "maybe appropriate" for patients with such limited life expectancy. The AUC document further identifies TAVR as possibly appropriate in patients with functional status more limited by their comorbidities than by their AS. These "cohort C" patients, as they were formerly called, are likely dying with AS rather than of it. Favoring utilization of TAVR in both these circumstances places clinicians at significant ethical and medicolegal risk when they choose an action not supported by established guidelines. ${ }^{8}$ This discordance between the AUC document and established guidelines will confuse patient care, draw the attention of payor scrutiny, and at some point affect financial reimbursement. AUC influence on US Centers for Medicare and Medicaid Services reimbursement has already begun with respect to medical imaging, and influences of AUC documents are certain to become more commonplace. ${ }^{9}$

Finally, Bonow and colleagues ${ }^{1,2}$ acknowledge that many patients seen in todays' multidisciplinary clinics do present with myriad concomitant coronary and other valvular diseases. These cases are perhaps the most complex, and the combinations of choice, timing, number, and route of interventions for them are many. It is not surprising that the tables (Tables 4 and 5) in the AUC document ${ }^{1,2}$ used to describe these patient scenarios are lengthy and yet still do not encompass the anatomic and procedural risks. Although SYNTAX scores are helpful, they are unlikely, as current practice has suggested, to drive clinical decisions. ${ }^{10}$
The utility of such cumbersome tables is limited, with Bonow and colleagues", acknowledging that "optimal management of CAD [coronary artery disease] in patients with AS...is best achieved with close collaboration between Heart Team Members." It becomes inherently problematic then, with patients of this degree of complexity, to rate decisions as anything other than "maybe appropriate." Suggestions of "rarely appropriate" or "always appropriate" are often unfounded, appear to be based solely on opinions, and may do more to harm than to help the treating physician in making a clinical decision. Similar criticisms of the AUC are likely to apply to the algorithms regarding treatment of the ascending aorta associated with bicuspid valve disease and therapies needed for concomitant valve disease. For example, the strong insinuation that an 82-year-old patient with a heavily calcified bicuspid valve, Society of Thoracic Surgeons score of 8 , and ascending aorta of $4.5 \mathrm{~cm}$ should have the ascending aorta replaced, or that a MitraClip (Abbott Laboratories, Abbott Park, Ill) ought to be considered in any instance for functional mitral regurgitation before US Food and Drug Administration approval has been granted, is inappropriate, and perhaps even dangerous. ${ }^{11,12}$

In conclusion, the intent of the AUC document to clarify choices for the treatment of AS and clarify gaps within established, published guidelines is a noble endeavor. However, using expert opinion to create algorithms that have the same look and feel as current guidelines, but without the same level of evidence, is fraught with peril. Much of what we know about the treatment of AS with TAVR and SAVR does come form recent multicenter, randomized trials. Until we have more data, the best recommendation for the treatment of these complex patients is the class Ia recommendation from the AHA's and European societies' guidelines, emphasizing the importance of the heart team.

\section{Conflict of Interest Statement}

Authors have nothing to disclose with regard to commercial support.

\section{References}

1. Bonow RO, Brown AS, Gillam LD, Kapadia SR, Kavinsky CJ, Lindman BR, et al ACC/AATS/AHA/ASE/EACTS/HVS/SCA/SCAI/SCCT/SCMR/STS 2017 appropriate use criteria for the treatment of patients with severe aortic stenosis: a report of the American College of Cardiology appropriate use criteria task force, American Association for Thoracic Surgery, American Heart Association, American Society of Echocardiography, European Association for Cardio-Thoracic Surgery, Heart Valve Society, Society of Cardiovascular Anesthesiologists, Society for Cardiovascular Angiography and Interventions, Society of Cardiovascular Computed Tomography, Society for Cardiovascular Magnetic Resonance, and Society of Thoracic Surgeons. J Am Coll Cardiol. 2017;70:2566-98.

2. Bonow RO, Brown AS, Gillam LD, Kapadia SR, Kavinsky CJ, Lindman BR, et al. ACC/AATS/AHA/ASE/EACTS/HVS/SCA/SCAI/SCCT/SCMR/STS 2017 appropriate use criteria for the treatment of patients with severe aortic stenosis: a report of the American College of Cardiology appropriate use criteria task force, American Association for Thoracic Surgery, American Heart Association, American Society of Echocardiography, European Association for Cardio- 
Thoracic Surgery, Heart Valve Society, Society of Cardiovascular Anesthesiologists, Society for Cardiovascular Angiography and Interventions, Society of Cardiovascular Computed Tomography, Society for Cardiovascular Magnetic Resonance, and Society of Thoracic Surgeons. J Am Soc Echocardiogr. 2018; 31:117-47.

3. Makkar RR, Fontana GP, Jilaihawi H, Kapadia S, Pichard AD, Douglas PS, et al; PARTNER Trial Investigators. Transcatheter aortic valve replacement for inoperable severe aortic stenosis. N Engl J Med. 2012;366:1696-704.

4. Reardon MJ, Van Mieghem NM, Popma JJ, Kleiman NS, Søndergaard L, Mumtaz M, et al; SURTAVI Investigators. Surgical or transcatheter aorticvalve replacement in intermediate-risk patients. $N$ Engl J Med. 2017;376: 1321-31.

5. Leon MD, Smith CR, Mack MJ, Makkar RR, Svensson LG, Kodali SK, et al; PARTNER 2 Investigators. Transcatheter or surgical aortic-valve replacement in intermediate-risk patients. $N$ Engl J Med. 2016;374:1609-20.

6. Nishimura RA, Otto CM, Bonow RO, Carabello BA, Erwin JP III, Guyton RA, et al; ACC/AHA Task Force Members. 2014 AHA/ACC guideline for the management of patients with valvular heart disease: a report of the American College of Cardiology/American Heart Association Task Force on Practice Guidelines. Circulation. 2014;129:e521-643. Erratum in: Circulation. 2014;130:e120. Erratum in: Circulation. 2014;129:e651.
7. Baumgartner H, Falk V, Bax JJ, De Bonis M, Hamm C, Holm PJ, et al; ESC Scientific Document Group. 2017 ESC/EACTS guidelines for the management of valvular heart disease. Eur Heart J. 2017;38:2739-91.

8. Fogel RI, Epstein AE, Mark Estes NA III, Lindsay BD, DiMarco JP, Kremers MS, et al. The disconnect between the guidelines, the appropriate use criteria, and reimbursement coverage decisions: the ultimate dilemma. J Am Coll Cardiol. 2014;63:12-4.

9. Centers for Medicare \& Medicaid Services. Medicare program: hospital outpatient prospective payment and ambulatory surgical center payment systems and quality reporting programs. 82 Federal Register 59216 (2016). Available at: https://www federalregister.gov/documents/2017/12/14/R1-2017-23932/medicare-programhospital-outpatient-prospective-payment-and-ambulatory-surgical-center-payment.

10. Taggart DP. Percutaneous or surgical revascularization in multivessel coronary artery disease: synthesis from SYNTAX. Eur Heart J. 2014;35:2789-91.

11. US National Library of Medicine, ClinicalTrials.gov. Cardiovascular Outcomes Assessment of the MitraClip Percutaneous Therapy for Heart Failure Patients with Functional Mitral Regurgitation (The COAPT Trial) (COAPT) NCT01626079. Available at: https://clinicaltrials.gov/ct2/show/NCT01626079.

12. Kaneko T, Shekar P, Ivkovic V, Longford NT, Huang CC, Sigurdsson MI, et al, Should the dilated ascending aorta be repaired at the time of bicuspid aortic valve replacement? Eur J Cardiothorac Surg. 2018;53:560-8. 